Conf-950291-.1

UCRL-JC-119533

PREPRINT

\title{
Feasibility of Organo-Beryllium Target Mandrels Using Organo-Germanium PECVD as a Surrogate
}

\author{
R. M. Brusasco \\ T. Dittrich \\ R. C. Cook
}

This paper was prepared for submittal to the 10th Target Fabrication Specialists' Meeting

Taos, New Mexico

February 6-9, 1995

March 9, 1995

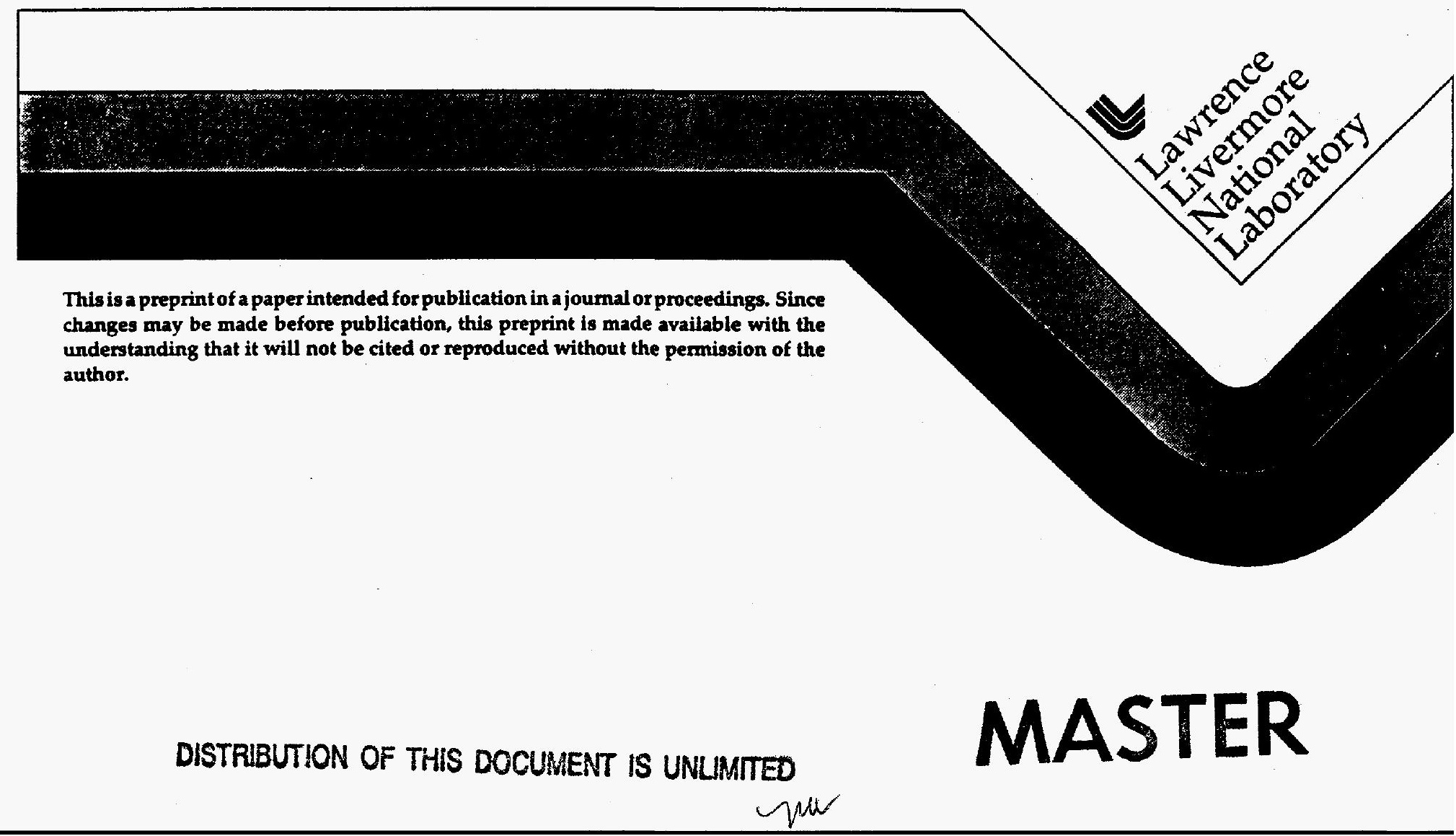


DISCLAIMER

This document was prepared as an account of work sponsored by an agency of the United States Government. Neither the United States Government nor the University of California nor any of their employees, makes any warranty, express or implied, or assumes any legal liability or responsibility for the accuracy, completeness, or usefulness of any information, apparatus, product, or process disclosed, or represents that its use would not infringe privately owned rights. Reference herein to any specific commercial product, process, or service by trade name, trademark, manufacturer, or otherwise, does not necessarily constitute or imply its endorsement, recommendation, or favoring by the United States Government or the University of California. The views and opinions of authors expressed herein do not necessarily state or reflect those of the United States Government or the University of California, and shall not be used for advertising or product endorsement purposes. 


\section{DISCLAIMER}

Portions of this document may be illegible in electronic image products. Images are produced from the best available original document. 


\section{FEASIBILITY OF ORGANO-BERYLLIUM TARGET MANDRELS USING ORGANO- GERMANIUM PECVD AS A SURROGATE}

Raymond Brusasco Lawrence Livermore National Laboratory P.O. Box 5508-L-482 Livermore, CA 94551
Thomas Dittrich Lawrence Livermore National Laboratory P.O. Box 5508-L-477 Livermore, CA 94551
Robert Cook Lawrence Livermore National Laboratory P.O. Box 5508-L-482 Livermore, CA 94551

\section{ABSTRACT}

Inertial Confinement Fusion capsules incorporating beryllium are becoming attractive for use in implosion experiments designed for modest energy gain. This paper explores the feasibility of chemical vapor deposition of organo-beryllium precursors to form coating materials of interest as ablators and fuel containers. Experiments were performed in a surrogate chemical system utilizing tetramethylgermane as the organometallic precursor. Coatings with up to 60 mole percent germanium were obtained. These coatings compare favorably with those previously reported in the literature and provide increasing confidence that a similar deposition process with an organo-beryllium precursor would be successful.

\section{INTRODUCTION}

One of the goals of the proposed National Ignition Facility (NIF) is to produce modest energy gain in Inertial Confinement Fusion (ICF) implosions. Present day implosions are being performed using fuel capsules made from carbon based materials. For the NIF, however, capsule materials based upon beryllium may be more suitable because of hydrodynamic efficiency and stability issues.

The requirements associated with the practical production of ICF fuel capsules, namely the need for diffusional hydrogenic fuel filling, a high degree of sphericity and very smooth inner and outer surfaces, makes the use of beryllium in an ICF capsule a challenging materials processing task. Existing beryllium processing technologies, such as machining, plasma spray and thermal evaporation, while attractive because of the established technological base, have inherent limitations in direct application for ICF target fabrication. The use of pure beryllium metal may not be feasible or even desirable, from a target physics point of view. As an alternative to conventional fabrication technology, this paper discusses the feasibility of the plasma polymerization of organo-beryllium feedstocks as a route toward the fabrication of ICF capsules. 
Plasma polymerization is currently being used to fabricate the organic ablator coatings on ICF targets and is capable of producing smooth surface finishes, of the order of $9 \mathrm{~nm}$ rms.1,2 Conceptually, it might be possible to co-deposit beryllium and organic plasma polymer so as to form a homogeneous and amorphous phase of. material which is enriched in beryllium. Such a phase would be expected to be smooth since it is deposited in a molecular manner, as is the case with the current all-organic plasma polymer coatings. The combination of an intimately mixed carbon and beryllium phase should be amenable to diffusion filling of hydrogenic fuel. Finally, the plasma polymerization process possesses great flexibility in doping coatings with other elements, such as germanium, ${ }^{3}$ bromine, ${ }^{1}$ silicon ${ }^{4}$ and the like.

\section{THEORETICAL BASIS FOR PREPARING ORGANO-BERYLLIUM COATINGS AND THEIR IMPLOSION PERFORMANCE}

Although still in a preliminary state, calculations on the performance of ICF target capsules using a variety of construction materials indicate that pure beryllium may not be the best choice for a fuel container. Current capsule designs utilize a solid DT main fuel layer surrounded by an ablator material. The kinetic energy imparted to this main fuel layer during implosion can be calculated and used as a figure of merit for comparing various ablator materials. Figure 1 plots the calculated maximum main fuel kinetic energy in jerks ( 1 jerk $=10^{16}$ ergs) versus initial capsule ablator thickness, for capsules with four different ablator materials which vary from pure beryllium to pure carbon.

Figure 1. Plot of the calculated main fuel kinetic energy as a function of initial capsule ablator thickness for several capsule compositions. The locus of "burn-through" points is overlaid on the graphs (see text for discussion).

The circles on each curve locates the so-called "burn-through" point in the ablator thickness. Ablators thinner than the burn-through point will be fully volatilized during the acceleration of the target to convergence and implosion efficiency and fuel mass will be wasted in the ablation process, making ablators thinner than the burn-through point useless for ICF experiments. The locus of burn-through points for the various ablator materials is overlaid on the plot. It can be seen that capsule materials with compositions of the order of 50 mole percent carbon have much higher main fuel kinetic energies near the burn-through point than pure beryllium. Figure 1 does not contain any information regarding sensitivity to hydrodynamic instabilities where beryllium incorporation is expected to significantly improve capsule performance. Although extremely simplistic, figure 1 suggests that a carbon-beryllium plasma polymer with a considerable amount of carbon present would be attractive as an ICF capsule material. 
The dialkylberyllium precursors which may be most useful for plasma polymerization are dimethylberyllium $\left(\mathrm{Be}\left(\mathrm{CH}_{3}\right)_{2} \mathrm{CAS}\right.$ No. 506-63-8), diethylberyllium ( $\mathrm{Be}\left(\mathrm{C}_{2} \mathrm{H}_{5}\right)_{2} \mathrm{CAS} \mathrm{No}$. 542-63-2) and di-tert-butylberyllium

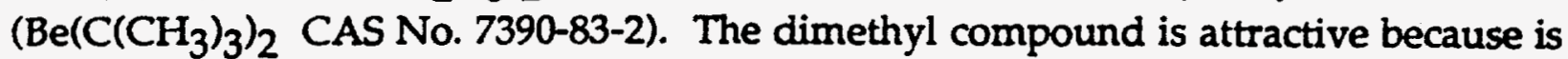
carries the least amount of carbon per mole of beryllium. This material is a sublimable solid and thus would require transport into the plasma polymerization process under above ambient temperature conditions. Diethylberyllium has a greater vapor pressure (approximately $1.6 \mathrm{Torr}$ at $25^{\circ} \mathrm{C}$ and 27 Torr at $85^{\circ} \mathrm{C}$ ) and is appealing because it is a commercially available compound. Finally, di-tertbutylberyllium has the highest vapor pressure of all the dialkylberyllium materials ( 35 to 40 Torr at $25^{\circ} \mathrm{C}$ ) and is thus easiest to transport into the plasma polymerization process, regardless of the amount of carbon transported as well.

The toxic nature of the organo-beryllium precursors has precluded any direct experimental work at the present time. However, a suitable surrogate system was used to provide some insight as to the nature of highly metal doped plasma polymer coatings. The plasma polymerization of tetramethylgermane (TMG) provides the most convenient chemical system for study. TMG is a safe, convenient, metal-alkyl with adequate volatility. Surrogate alkaline earth precursors other than beryilium all contain oxygenated ligands and have been developed primarily for application in preparing high temperature superconducting coatings. Since their use in plasma polymerization would create oxidized coatings, they were not considered useful in this study. TMG has been used successfully as a plasma polymer dopant in this laboratory and is thus very compatible with organic plasma polymer coatings. Also, the literature contains several examples of organogermanium coatings using tetra-alkyl germanium precursors. Some of these coatings are reported to have very high metal-to-carbon ratios.

\section{EXPERIMENTAL BASIS FOR ORGANO-GERMANIUM COATING WORK}

Gazicki et al. attempted to prepare germanium carbide films from the plasma polymerization of tetraethylgermane using a uniquely designed RF magnetron plasma source. 5 They found that their coatings were more organic-like, based on the results of their density measurements. The coatings produced in their study had germanium-to-carbon ratios in the range of 0.06 to 0.17 . Tyczkowski $e t$ al. have also deposited amorphous germanium-carbon-hydrogen films using a three-electrode reactor at $20 \mathrm{kHz}$ and TMG as the precursor. ${ }^{6}$ Their films had germanium-to-carbon ratios ranging from 0.09 to 0.33 and were generally similar to those produced by Gazicki et al.

Sadhir et al. have deposited organo-germanium films using TMG in a 13.56 $\mathrm{MHz}$ coil reactor but in a unique configuration. ${ }^{7}$ Instead of placing substrates downstream, below the active plasma zone, the substrates were placed upstream and ahead of the plasma "hot spot." These coatings are reported to have germanium-to- 
carbon ratios as high as $7.4: 1(88 \%)$ and were reported to possess semiconductor electrical characteristics. This work would suggest that very high metal content could be obtained only in an "upstream" deposition configuration. Since our deposition equipment does not allow for convenient "upstream" processing, it was necessary to characterize our coating system both above and below the plasma zone.

To accomplish this, an optical fiber was suspended inside the plasma envelope of a helical resonator plasma polymerization coater, which has been described in the literature previously. 8 Coatings on this fiber were characterized for germanium content via $X$-ray Microfluorescence (XRF) and thickness via Scanning Electron Microscopy of cross-sections at the point of XRF characterization. The mass was determined by weighing fiber segments and the volume calculated from geometrical considerations. From these data, the coating density and the metal-tocarbon ratio was determined as a function of axial position, assuming a generic coating chemical formula of $\mathrm{C}_{\mathrm{x}} \mathrm{Ge}_{\mathrm{y}}$. We have chosen to ignore the hydrogen content since it is a minor component on a weight basis. Table I contains the operating parameters used to perform these deposition experiments.

\section{EXPERIMENTAL RESULTS}

Figure 2 plots the thickness in micrometers and the germanium content in grams per cubic centimeter of coatings deposited along the bore of the plasma polymerization device. The zero point in distance corresponds roughly to the first visual indication of a coating within the plasma tube. For reference, the plasma tube outlet is about $80 \mathrm{~mm}$ downstream.

Figure 2. Plot of the thickness $(\mu \mathrm{m})$ and germanium content $\left(\mathrm{g} \mathrm{cm}^{-3}\right)$ for an organo-germanium coating deposited axially in the helical resonator plasma polymerization system.

As is typical of this type of coating device, the coating deposits rapidly at the point of the plasma "hot spot" with the deposition rate decreasing monotonically past the power deposition zone and out of the plasma tube. The germanium content of the coating rises sharply upon deposition to a roughly constant value, then appears to increase upon exit of the plasma tube. This would tend to indicate some sort of transport mechanism of germanium out of the plasma applicator, probably mediated by the high hydrogen concentration and the existence of plasma along the applicator.

The mass of the coating at each point measured in Figure 2 was determined and the volume was calculated assuming a right cylinder for each fiber segment. Upon subtracting the mass contribution due to the glass fiber, the density of the coating on the fiber was determined. Figure 3 plots the density of the coating as a 
function of distance along the fiber. Data beyond approximately $80 \mathrm{~mm}$ down from the start of deposition were unobtainable due to the fragile nature of the coatings; large pieces of the coating flaked off during handling while weighing. This problem does not invalidate the germanium content determinations given in figure 2 since minimal handling was needed to obtain that data. The average density of the coating within the plasma envelope is $2.71 \mathrm{~g} \mathrm{~cm}^{-3}$. Insufficient information exists to determine the reproducibility of the density versus axial position. We assume an error bar for any measurement to be $\pm 10-20 \%$, due entirely to calculating the volume of coating.

Figure 3. Plot of the coating density $\left(\mathrm{g} \mathrm{cm}^{-3}\right)$ versus distance along the optical fiber. Coatings from $80 \mathrm{~mm}$ were too thin and fragile to survive handling in the mass determination step.

Given both the germanium content of the coating and the overall density, and assuming that the coating has a generic formula of $\mathrm{C}_{x} \mathrm{Ge}_{y}$, the empirical formula of the coatings as a function of axial position was calculated. The result of this determination appears in figure 4 , where the mole fraction germanium is plotted as a function of axial position down the length of the plasma envelope.

Figure 4. Plot of the mole fraction of germanium as a function of axial position within the plasma applicator.

As with the density determinations given in Figure 3, there is insufficient information to assure reproducibility in terms of axial position but it is apparent that the coatings produced under the conditions given in Table I have a germanium content that can be as high as 60 mole percent. Based on this fact, one might expect coatings with up to 60 mole percent beryllium to be feasible.

\section{SAFETY CONCERNS REGARDING ORGANO-BERYLLIUM DEPOSITION}

The organometallic precursors for beryllium discussed are pyrophoric and thus present an extreme berylliosis hazard in terms of the propensity to form fine particulate $\mathrm{BeO}$. Fortunately, such materials can be handled with relative safety in glove boxes. Figure 5 presents a schematic outline for a coating system designed for the safe handling of these compounds as well as managing the results of credible accident scenarios.

Figure 5. Schematic diagram of an organo-beryllium plasma polymerization coating system. 
For maximum protection, the organo-beryllium precursor could be synthesized on an as-needed basis in a glove box purged with dry argon. The glove box vent must be processed to remove organo-beryllium vapors should there be a spill of the pyrophoric material. Organo-beryllium compounds are quantitatively reduced to beryllium metal via pyrolysis above about $300^{\circ} \mathrm{C}$. Thus, pyrolysis furnaces placed on gas stream outlets should destroy any organo-beryllium vapors that should escape. The outlet of the furnace may be equipped with HEPA filters or a second stage treatment of dilute aqueous acid gas scrubbing.

The coating system must be located in an appropriately designed fume hood with HEPA filtration. The coating process itself does not create beryllium contaminated dust but residual vapors in the system after an experiment must be properly vented and treated before release to the environment. The effluent gas from the process can be scrubbed of volatile beryllium via the same pyrolysis process described above, which has the added advantage of potentially eliminating beryllium contamination of the vacuum pumping system.

\section{CONCLUSIONS}

It has been shown that the plasma polymerization of organo-beryllium precursors is a feasible process and may produce a material which is attractive for use as the capsule material in an ICF target designed for ignition. Extrapolations based on a surrogate chemical system using germanium instead of beryllium suggest that coatings with metal content as high as 60 mole percent could be realized. Although the hazards associated with the starting materials are great, a coating system can be designed to mitigate these hazards and allow for development of the process. We are now in the process of modifying our coating facility to handle organo-beryllium precursors and will be preparing coatings within the year.

\section{ACKNOWLEDGMENTS}

The authors would like to gratefully acknowledge the technical assistance of Anselmo Dueñas, Ed Lindsey, Craig Moore, Robert Turner and Larry Witt, all at the Lawrence Livermore National Laboratory. This work was performed under the auspices of the U.S. Department of Energy by Lawrence Livermore National Laboratory under Contract W-7405-ENG-48. 


\section{Table I}

Operating parameters for organo-germanium coating formation

$\mathrm{H}_{2}$ flow rate

TMG flow rate

Chamber pressure

RF Power

Coating time
$13 \mathrm{sccm}$

$0.27 \mathrm{sccm}$

$70 \mathrm{mTorr}$

$12 \mathrm{~W}$

4 hours 


\section{List of Figures}

Figure 1 Plot of the calculated main fuel kinetic energy as a function of initial capsule ablator thickness for several capsule compositions. The locus of "burn-through" points is overlaid on the graphs (see text for discussion).

Figure 2 Plot of the thickness $(\mu \mathrm{m})$ and germanium content $\left(\mathrm{g} \mathrm{cm}^{-3}\right)$ for an organo-germanium coating deposited axially in the helical resonator plasma polymerization system.

Figure 3 Plot of the coating density $\left(\mathrm{g} \mathrm{cm}^{-3}\right)$ versus distance along the optical fiber. Coatings from $80 \mathrm{~mm}$ were too thin and fragile to survive handling in the mass determination step.

Figure 4 Plot of the mole fraction of germanium as a function of axial position within the plasma applicator.

Figure 5 Schematic diagram of an organo-beryllium plasma polymerization coating system. 


\section{REFERENCES}

1S.A. Letts, R.C. Cook, P. Welch, R. McEachern and E. Fearon, "The effects of process parameters on the surface finish of plasma polymers," Report CONF-930304, 28 March - 2 April, 1993, p 323, 205 th American Chemical Society National Meeting, Denver, CO, (1993).

${ }^{2}$ G.W. Collins, S.A. Letts, E.M. Fearon, R.L. McEachern and T.P. Bernat, "Surface Roughness Scaling of Plasma Polymer Films," Phys. Rev. Lett., 3(5), 708 (1994). $3_{R}$. Brusasco, M. Saculla and R. Cook, "Preparation of Germanium Doped Plasma Polymerized Coatings as ICF Target Ablators," to be published in Journal of Vacuum Science and Technology.

4S.A. Letts, D.E. Miller, R.A. Corley, T.M. Tillotson and L.A. Witt, "Microspot Target Development with Seeded and Patterned Plasma Polymers," Report UCRL-90938, December 3, 1984, $31^{\text {st }}$ American Vacuum Society National Symposium, Reno, NV, (1984).

5M. Gazicki, J. Schalko, F. Olcaytug, M. Ebel, H. Ebel, J. Wernisch and H. Yasuda, "Study on electromagnetron for plasma polymerization. II. Magnetic field enhanced radio frequency plasma deposition of organogermanium films from tetraethylgermanium," J. Vac. Sci. Tech. A, 12(2), 345 (1994).

6J. Tyczkowski, P. Kazimierski and H. Szymanowski, "Correlations between process parameters, chemical structure and electronic properties of amorphous hydrogenated $\mathrm{Ge}_{\mathbf{x}} \mathrm{C}_{1-\mathrm{x}}$ films prepared by plasma-enhanced chemical vapour deposition in a three-electrode reactor," Thin Solid Films, 241, 291 (1993).

${ }^{7}$ R.K. Sadhir, H.E. Saunders and W.A. Byers, "Plasma Polymerized Tetramethyl Germanium Films Deposited at Elevated Substrate Temperatures," Polym. Eng. Sci., 33(10), 645 (1993).

8S.W. Ferguson, S.W., R. Stever and R.M. Brusasco, "Impedance-Power Effects on Plasma Polymer Surface Finish Using a Helical Resonator Discharge," J. Appl. Polym. Sci. Appl. Polym. Symp., 54, 107 (1994). 


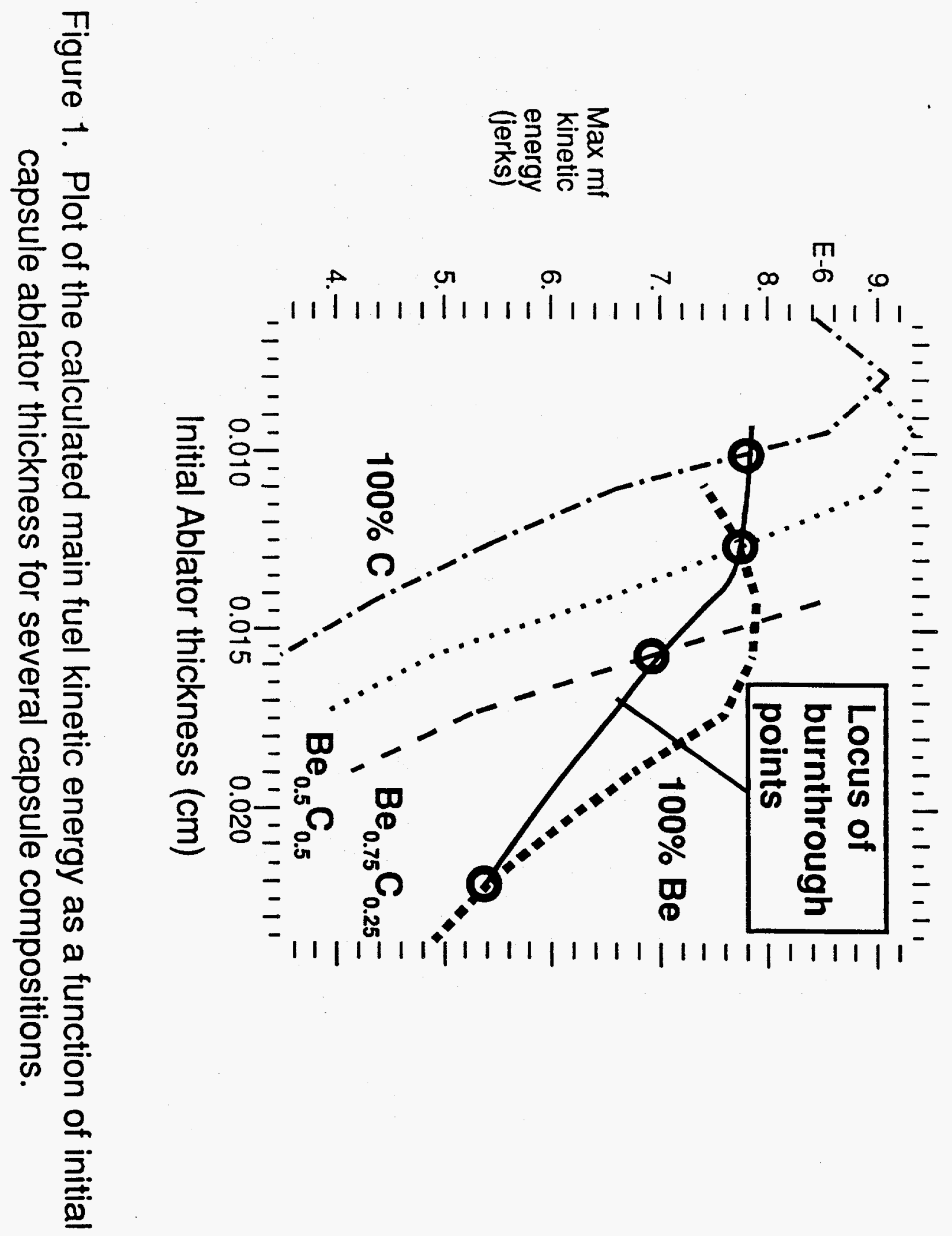




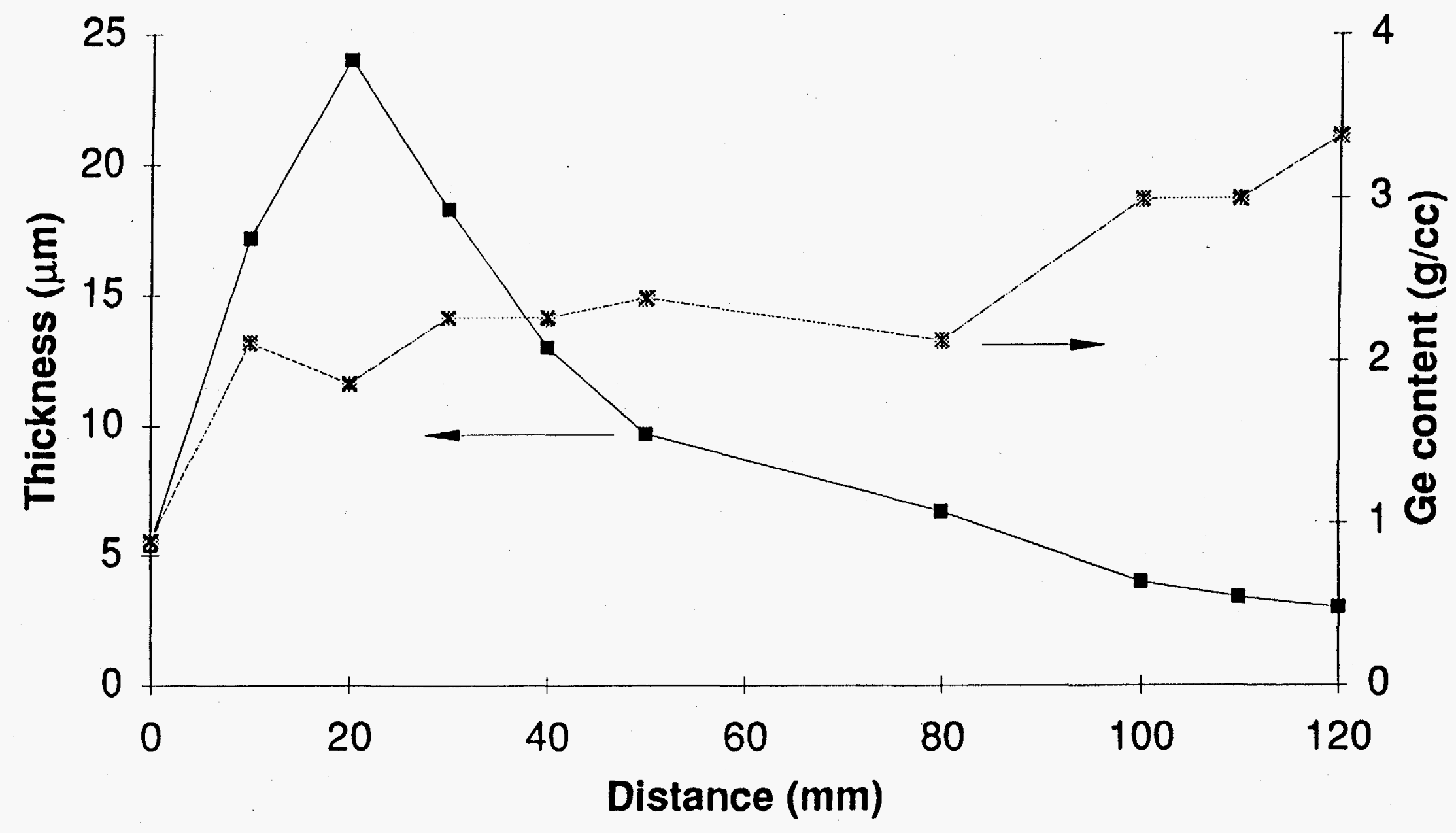

Figure 2. Plot of the thickness $(\mu \mathrm{m})$ and density of germanium $\left(\mathrm{g} / \mathrm{cm}^{\wedge} 3\right)$ for an organogermanium coating deposited axially in the helical resonator plasma polymerization system. 


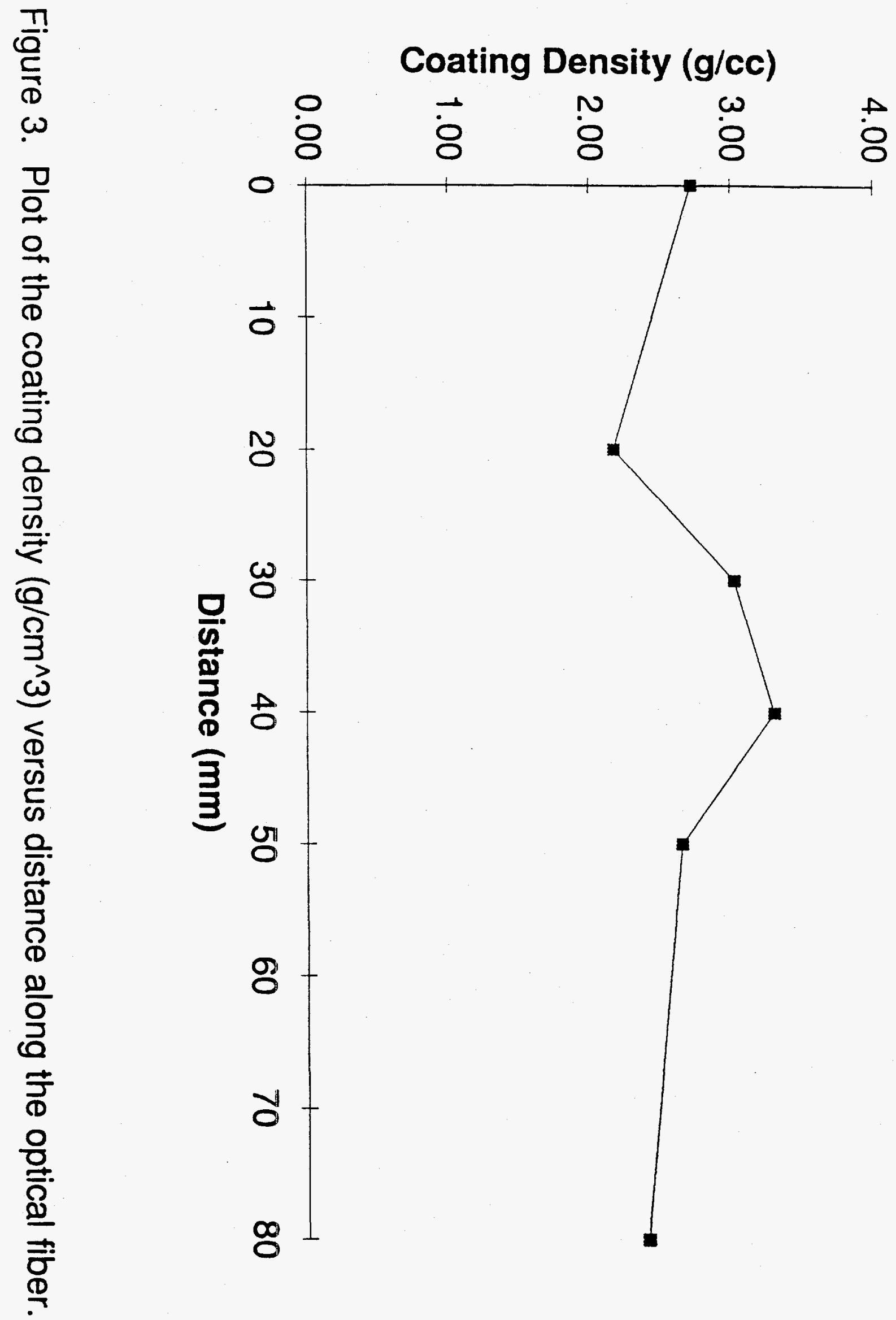




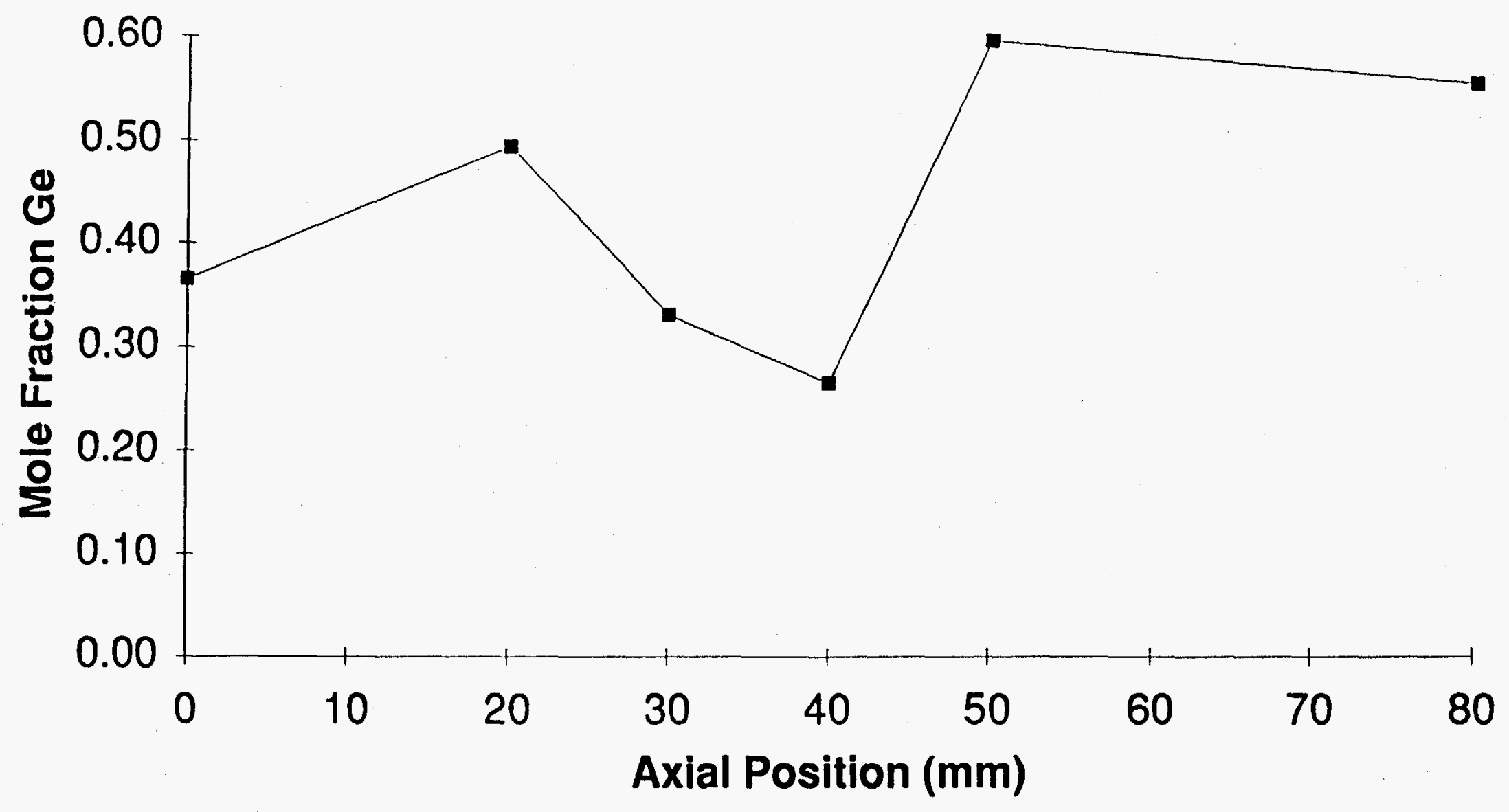

Figure 4. Plot of the mole fraction of germanium as a function of axial position within the plasma applicator. 

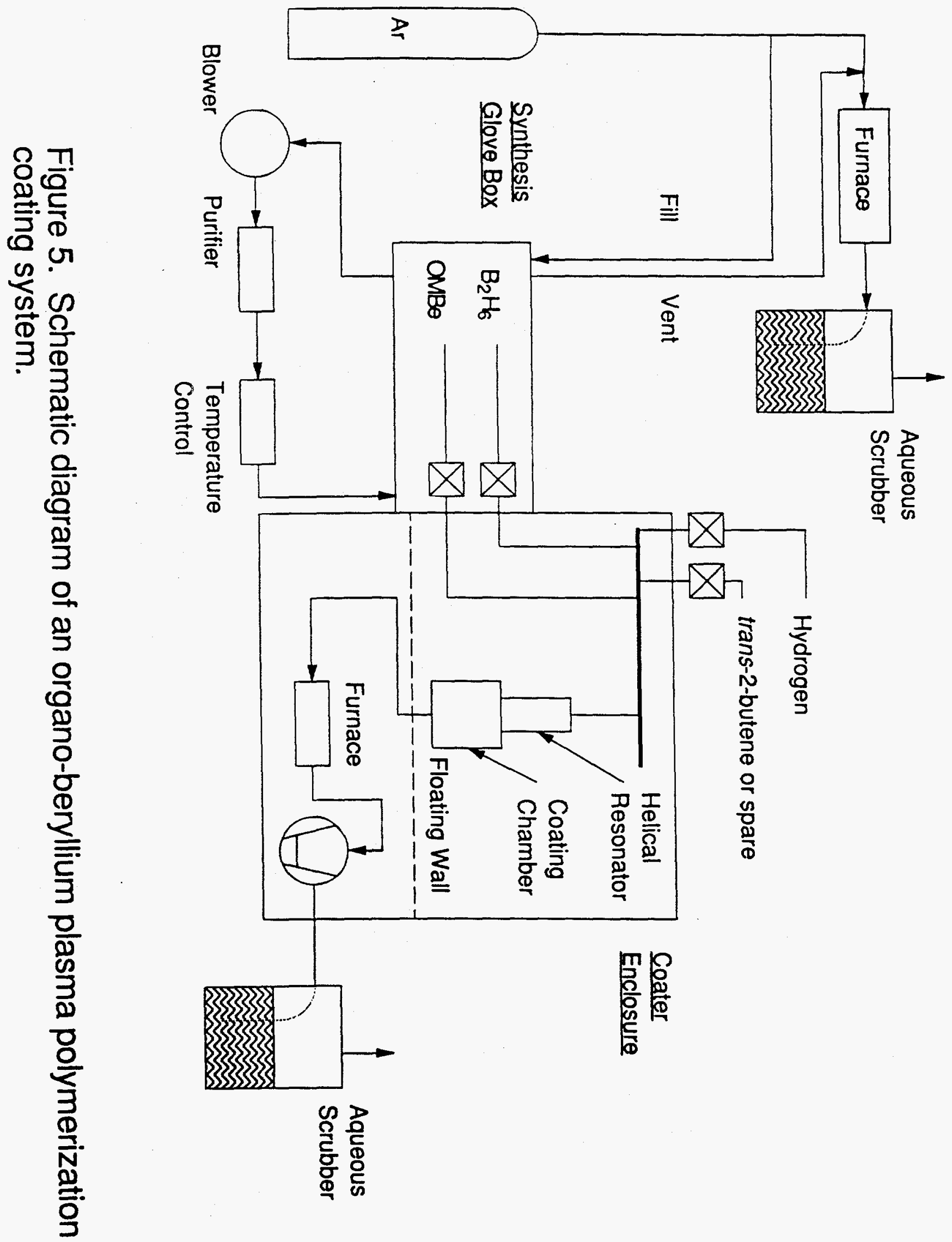